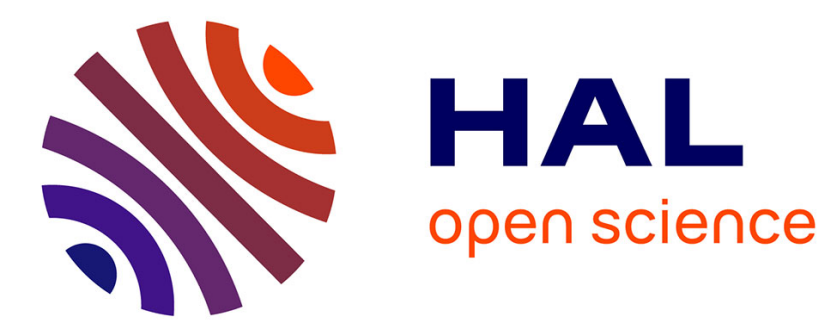

\title{
Feeding everyone if the sun is obscured and industry is disabled
}

\author{
David C Denkenberger, D. Dorothea Dorothea Cole, Mohamed Abdelkhaliq, \\ Michael Griswold, Allen B Hundley, Joshua Pearce
}

\section{- To cite this version:}

David C Denkenberger, D. Dorothea Dorothea Cole, Mohamed Abdelkhaliq, Michael Griswold, Allen B Hundley, et al.. Feeding everyone if the sun is obscured and industry is disabled. International Journal of Disaster Risk Reduction, 2017, 21, pp.284-290. 10.1016/j.ijdrr.2016.12.018 . hal-02113471

\section{HAL Id: hal-02113471 https://hal.science/hal-02113471}

Submitted on 28 Apr 2019

HAL is a multi-disciplinary open access archive for the deposit and dissemination of scientific research documents, whether they are published or not. The documents may come from teaching and research institutions in France or abroad, or from public or private research centers.
L'archive ouverte pluridisciplinaire HAL, est destinée au dépôt et à la diffusion de documents scientifiques de niveau recherche, publiés ou non, émanant des établissements d'enseignement et de recherche français ou étrangers, des laboratoires publics ou privés. 
Preprint: David C. Denkenberger, D. Dorothea Cole, Mohamed Abdelkhaliq, Michael Griswold, Allen B. Hundley, Joshua M. Pearce. Feeding Everyone if the Sun is Obscured and Industry is Disabled. International Journal of Disaster Risk Reduction 21, (2017), 284-290. DOI: 10.1016/j.ijdrr.2016.12.018

\title{
Feeding Everyone if the Sun is Obscured and Industry is Disabled
}

David C. Denkenberger, ${ }^{1,2}$ D. Dorothea Cole,${ }^{1}$ Mohamed Abdelkhaliq, ${ }^{1}$ Michael Griswold, ${ }^{1}$ Allen B. Hundley, ${ }^{3}$ Joshua M. Pearce ${ }^{4}$

${ }^{1}$ Tennessee State University, 3500 John A Merritt Boulevard

Nashville, TN 37209, USA. E-mail: ddenkenb@tnstate.edu;

${ }^{2}$ Global Catastrophic Risk Institute, USA. E-mail: david.denkenberger@gmail.com

${ }^{3}$ Technical Consultant, Manistique, Michigan, USA

${ }^{4}$ Michigan Technological University, Houghton, Michigan, USA.

Keywords: nuclear war; global catastrophic risk; existential risk; solar storm; electromagnetic pulse; cyber attack;

\begin{abstract}
:
A number of catastrophes could block the sun, including asteroid/comet impact, super volcanic eruption, and nuclear war with the burning of cities (nuclear winter). The problem of feeding 7 billion people would arise (the food problem is more severe than other problems associated with these catastrophes). Previous work has shown this is possible converting stored biomass to food if industry is present. A number of risks could destroy electricity globally, including a series of high-altitude electromagnetic pulses (HEMPs) caused by nuclear weapons, an extreme solar storm, and a super computer virus. Since industry depends on electricity, it is likely there would be a collapse of the functioning of industry and machines. Additional previous work has shown that it is technically feasible to feed everyone given the loss of industry without the loss of the sun. It is possible that one of these sun-blocking scenarios could occur near in time to one of these industry-disabling scenarios. This study analyzes food sources in these combined catastrophe scenarios. Food sources include extracting edible calories from killed leaves, growing mushrooms on leaves and dead trees, and feeding the residue to cellulose-digesting animals such as cattle and rabbits. Since the sun is unlikely to be completely blocked, fishing and growing ultraviolet (UV) and cold-tolerant crops in the tropics could be possible. The results of this study show these solutions could enable the feeding of everyone given minimal preparation, and this preparation should be a high priority now.
\end{abstract}

\section{Introduction}

A number of catastrophes could obscure the sun, including bolide (asteroid/comet) impact, supervolcanic eruption, and nuclear war with the burning of cities (nuclear winter) (Bostrom and Cirkovic, 2008). Blocking of the sun would result in the collapse of traditional agriculture and demand a new source of calories for the world's population.

In addition, there are several natural and human-caused catastrophes that could result in globalscale long-term electrical grid and/or electronics failure. The loss of the grid and/or elimination of all non-shielded electronics would be expected to halt the majority of industries and machines. A high-altitude electromagnetic pulse (HEMP) caused by a nuclear weapon could disable electricity over a large part of a continent (Foster, 2008). It is conceivable that multiple HEMPs could be produced around the world, due to a world nuclear war or from terrorists co-opting 
nuclear weapons. This could destroy the majority of electrical grid infrastructure globally, and as fossil fuel extraction and industry is dependent on electricity, industry could also be disabled (Foster, 2008). Similarly, solar storms have damaged transformers connected to long transmission lines (Board, 2008). There is evidence that within the last 2000 years, two solar storms occurred that were much more intense than modern society has endured (Mekhaldi et al., 2015). Though solar storms may last less than the half a day required to directly expose the entire earth, the earth's magnetic field lines redirect the storm to affect the opposite side of the earth (Board, 2008). Therefore, it is possible that an extreme solar storm could disable electricity globally. In addition, Stuxnet was a computer virus that disabled Iranian centrifuges (Kushner, 2013). There is evidence that a computer virus shut down electricity on a small scale (Goodin, 2016). It is possible that coordinated attacks on many electric grids could disrupt industry globally. An electricity-disabling event could occur in close temporal proximity to one blocking the sun. Furthermore, if a sunblocking scenario were to cause global cooperation to break down, industry could also collapse. It is the combination scenarios of losing industry and much sunlight that are the focus of this study.

Two estimates put the probability of full-scale nuclear war at order of magnitude $1 \%$ per year (Barrett et al., 2013; Hellman, 2008). Then there is uncertainty in whether this would cause agricultural collapse and whether it would cause industrial collapse. However, if these latter probabilities together are $1 \%$, this means there is a $0.01 \%$ chance per year that industry would collapse and $50 \%$ of the sun would be blocked. Given that there are other routes to losing the sun and industry, this gives roughly $1 \%$ chance this century. This scenario presents a grave threat to civilization, which could have repercussions for the far future. Because there are potentially so many future generations, the far future is of overwhelming importance (Beckstead, 2013).

The extended diminishment of the sun and loss of industry would present many problems. The first priorities are food, water, shelter and clothing as these are the basic necessities. With the loss of industry, provision of food is likely to be the greatest challenge, and this is the primary focus of the analysis presented here.

Additional challenges covered here include provision of water treatment and transportation to food and water sources. Previous work has analyzed provisioning needs in scenarios of the sun being blocked (Denkenberger and Pearce, 2014). In these scenarios, industry was assumed to remain functioning (Denkenberger and Pearce, 2015), which allows the possibility of maintaining near-current living locations and levels of consumption of goods. In this study, the additional collapse of industry precludes this so only a technical path to save nearly all human life in such a catastrophe is analyzed. We consider the worst-case scenario where industry is disrupted over an extended period.

\section{Background and Assumptions}

In some of the less challenging combined catastrophe scenarios, it may be possible to continue running the majority of machines for a short time with the fossil fuels that had previously been brought to the surface or from the use of microgrids or shielded electrical systems. Strategic petroleum reserves are typically underground, which may not be accessible. There is significant above-ground crude oil because much crude oil is shipped across the ocean and this takes a long 
time. Also, there is significant storage of coal at power plants. But the most valuable fuels likely would be gasoline and diesel. The net available shell storage capacity of terminals and tank farms in the U.S. is 40 billion L of gasoline and 30 billion L of diesel (Energy Information Administration, 2016). Though this capacity would not be fully utilized, this does not include the storage in pipelines, trucks, vehicle filling stations, and households. Therefore, we use these numbers a proxies for the storage, and multiply by five to estimate the global value. The fuel use rate of a chainsaw at near maximum power is $1.3 \mathrm{~L} / \mathrm{hr}$ (Magnusson et al., 2000). It would take $\sim 130$ billion chainsaw hours to fell and delimb all the tropical trees in the world (Denkenberger and Pearce, 2014). Therefore, it would require about $80 \%$ of gasoline storage to fell and delimb the tropical trees. The energy intensity of trucking is $2.2 \mathrm{MJ} /($ ton-km) (Brown and Hatch, 2002). If the weight of each person plus equipment and supplies is $120 \mathrm{~kg}$, to relocate 1 billion people $4000 \mathrm{~km}$ to the forests would require $18 \%$ of diesel storage. This is very conservative because much of the movement would be accomplished by far more efficient rail, and even trucks can be run more efficiently than currently.

Furthermore, natural gas would continue to bleed out of wells without any human input. It may be possible without large-scale industry to retrofit some vehicles to burn natural gas. Then the natural gas could be stored in large bags (Dartnell, 2014) or possibly compressed into tanks to allow longer distance trips. In addition, it is possible to run some machines on gasified wood (LaFontaine and Zimmerman, 1989). Repairing these systems and re-establishing electrical infrastructure would be a goal of the long term and this work would start immediately after a catastrophe. However, human needs would need to be met immediately (and continually) and here we focus on what is technically possible without the electrical infrastructure and half of sunlight, leaving economics and politics for future work.

Previous work has analyzed food sources as if they were individual, with the goal of ramping to $100 \%$ of human food requirements as quickly as possible. The present work recognizes that the goal would be a diversity of foods. Furthermore, the current analysis includes interactions between food sources, and allows the addition of each food source to a total supply similar to (Baum et al., 2015).

HEMPs could disable vehicles, including ships (Foster, 2008). However, these detonations would not likely be over open oceans, which means that many ships may still be operational. However, it is possible that a series of super computer viruses could disable ships through the Internet or GPS links. Ships may lose powered motion and continue to drift due to currents and winds. Currents alone would generally not bring ships to shore, but wind would. Empty ships and container ships with lower density cargo sit higher in the ocean and would be pushed faster by the wind. To extend the lives of the crew, solar stills could be improvised on the ships for freshwater production. There would be some food storage and it may be possible to improvise gear to harvest fish and edible seaweed. When the ship gets close to shore, or ahead of time if the people are going to die before reaching shore, it may be possible to let the anchor down to avoid the ship running aground and being damaged. However, storms could damage the drifting ships. The locations of some of the ships could be estimated by human memory and non-electronic records. Also, known shipping lanes could be targeted for rescue missions. Since the disabling of ships is not very likely and even if they were disabled there are number of retrieval options, we assume that all ships are available to use. 
The calculations are accurate to within an order of magnitude. However, when summing multiple food sources, the uncertainty decreases.

\section{Food}

\subsection{Stored Food and Agriculture in Reduced Solar Conditions}

Global grain production is $\sim 2.7$ billion tons (Gt)/yr (Tilman et al., 2002), and grains are 29\% total of fiber and moisture (Hurburgh, 2006; United States Department of Agriculture, 2006). Therefore, this is $\sim 1.9 \mathrm{Gt} / \mathrm{yr}$ dry carbohydrate equivalent. Grains make up half of the calories produced (Meadows et al., 2004); thus, the total food production is $\sim 3.8 \mathrm{Gt}$ dry/yr. The food requirement with low waste is $1.5 \mathrm{Gt} / \mathrm{yr}$ (Denkenberger and Pearce, 2014). Livestock consume $35 \%$ of the world's grain (Earth Policy Institute, 2011). Therefore, the initial state before the catastrophe shows a plant production of $210 \%$ of requirement (not including the part that goes to livestock) and $10 \%$ of requirement animal products (see Figure 1).

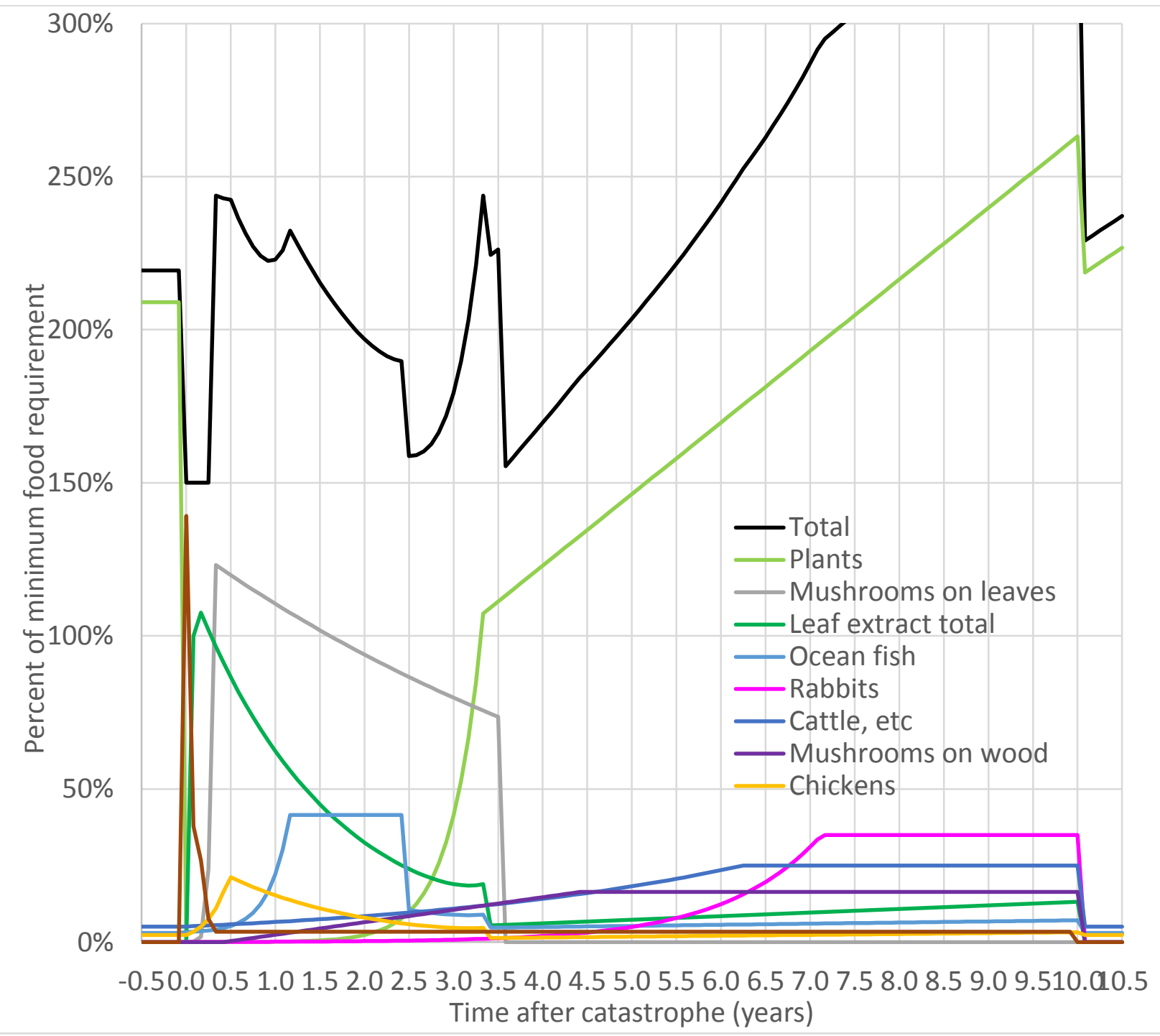


Figure 1. One possible scenario of the alternate foods supply as a function of time.

The average annual global wheat storage is 4 months at current wheat consumption (Do et al., 2010). Assuming this applies to all grains, there would be 5 months of full food from grain storage. In addition, we estimate that there is a 1-month supply at crisis levels of consumption of food total in the following locations: households, stores, and warehouses (livestock would generally be retained, but with alternate feed).

The soot released into the stratosphere from the burning of cities in a regional nuclear war would increase UV levels at the surface significantly (Mills et al., 2008). Full-scale nuclear war focused on here would be significantly worse (Bardeen unpublished results). The tropics would generally stay unfrozen, but even though crops currently grown outside the tropics would be able to tolerate the lower light, precipitation, and temperature, they generally would not be adapted for the high UV levels. One exception is crops being grown on the Tibetan plateau because of the thin high-altitude atmosphere. Here the UV index exceeds 16 for a significant amount of time (Chen et al., 2013). There is uncertainty, but roughly the UV levels in the tropics near sea level would recover to current Tibetan values after three years (Bardeen unpublished results).

Because a variety of crops is grown on the Tibetan plateau, this gives potential for handling different soil conditions in the tropics. There are also other high-altitude areas like the Andes from which crops could be relocated. Most crops now are grown outside their native habitat (Robinson, 2007), bolstering the feasibility of relocation.

Only about one percent of the total area of the Tibetan plateau is cultivated and two thirds of the total area or 165 million ha is classified as rangeland (Miller, 2003). Therefore, the cultivated area is approximately $25,000 \mathrm{~km}^{2}$. The number of seeds available from Tibet depends on the timing of the catastrophe. The best case would be at harvest, so that all seeds could be relocated and not eaten. The worst-case would be immediately after planting such that the plants would not mature and produce new seed. But even in this case, some seed would be withheld from planting as seed-producing operations will typically carry over 1-3 years of stock seed as insurance against a crop failure (Chester et al., 1988). Since one seed planted will produce approximately 100 seeds at harvest (Chester et al., 1988), we conservatively assume initial seed amounts 100 times lower than at harvest.

Since the yield is approximately 100 times as much as the planted seed, and we divide this by six to represent unfavorable climactic and industrial conditions. In reality, the yield per plant may not decrease as much as the yield per planted area. Furthermore, crops producing more seeds could be favored and they could be harvested twice per year in the tropics. Therefore, this ramping analysis is very conservative. To maximize the ramp rate of plants, only the part of the plants that are not seeds should be eaten initially.

With a growth rate of a factor of 16 per year, this would cover the entire tropical land area of 30 million $\mathrm{km}^{2}$ in approximately 3 years providing significant food as shown in Figure 1.

Soon after the catastrophe, UV levels may be too high to grow crops outdoors, but they could be grown under glass or polymer. Though there is limited supply of these materials, the initial area 
planted is small. During the first few generations, further UV resistance could be bred into the plants.

As the climate recovers, the productivity in the tropics would increase and planted area could be expanded. We estimate near full climate recovery after 15 years based on (Robock et al., 2007) and this corresponds to $380 \%$ as much as food requirements because entire current planted and forest area would be cultivated without industry (Cole et al., 2016). We assume that the productivity in the tropics once UV levels recover to that of Tibet would be approximately half as much as the normal climate, loss of industry scenario (which conservatively assumes preindustrial agricultural productivity and no substitution to higher calorie per hectare crops (Cole et al., 2016)). There would be significant fertilizer available from the conversion of leaves and wood. Also, tropical trees would be converted preferentially so that the time the tropics is covered with crops, much of the wood would be gone. Even in places where there is still wood, it would be possible with nonindustrial techniques to plant the crops between the logs. This alone produces enough food to feed everyone. If we were to instead take half the productivity of current Tibetan grains (4.5 ton/ha (Miller, 2003)), the amount of food produced would feed everyone three times over with just tropical area. Also, we ignore the possibility of grazing outside the tropics, so this analysis is conservative.

A number of experiments have subjected conventional crops to very high UV levels (Kakani et al., 2003). More work would be needed to fully simulate the conditions of nuclear winter in the tropics, but the results are encouraging. If conventional crops could be grown in the tropics immediately after the catastrophe, the supply from plants would be significantly higher in the first few years than shown in Figure 1.

Without mechanization, a farmer can grow four hectares of wheat, which would feed about 20 people (Langer, 1994). Unfavorable climate would worsen the situation, but still there is significant margin of safety from a labor perspective.

\subsection{Leaves}

The human-digestible fraction of the dry weight of killed tree leaves (as opposed to depleted leaves that are shed to become leaf litter) is approximately 50\% (Jacquemoud et al., 1996) and we assume this applies to all nonwoody biomass that is killed by the catastrophe. The promising nonindustrial technique to extract human food from leaves involves grinding and pressing leaves, and then coagulating (causing the solids to clump for removal) the resultant liquid (Kennedy and Leaf for Life, 1993). The hand powered equipment could be constructed without industry, but remaining fossil fuels could accelerate the process.

The global nonwoody vegetation is $~ 90 \mathrm{Gt}$ (Denkenberger and Pearce, 2014). With limited transportation capabilities, people would generally need to move to the leaves. In the case of tree leaves, this would then set the people up to convert the wood to food as well. Humans would carefully control competing mammals that could eat the dead leaves. Also, with the lower temperatures, competing insects would be less of a problem. 
The labor for harvesting the leaves could be minimized by running a gloved hand over the branch to strip many leaves/needles off at once. Chainsaws with residual fossil fuel could cut the trees down quickly.

If half of nonwoody biomass is nontoxic with 5\% dry matter extraction, it would be a 1.5 year supply of full human food. This could be ramped up very quickly because no organisms need to grow (see Figure 1). The remaining liquid that does not coagulate is brown. This could be fed to non-cellulose digesters such as chickens (see Figure 1).

Then the solids from the initial pressing could be fed to mushrooms or cellulose-digesting animals (ruminants, horses, rabbits, etc.), depending on availability of these organisms and demand for different types of food. In Figure 1, we assume this all goes to mushrooms because at least initially there are insufficient cellulose-digesting animals. These mushrooms would be grown indoors in existing structures, and temporary structures where necessary. The temporary structures could be log cabins or sod houses where there is not forest. White button mushrooms have a maximum biological efficiency (wet weight of mushrooms divided by dry weight of growing medium) of $100 \%$ (Chang and Miles, 1984) so with $90 \%$ water, this is $~ 10 \%$ caloric efficiency. We assume half the $10 \%$ value due to nonideal substrates and pests. Mushrooms could also grow on depleted leaves. With roughly twice the biomass available and the same conversion efficiency as leaf extraction, this could provide three years of full human food. Mushrooms can have billions of spores, so the ramp rate is very high.

The waste from the mushroom growth contains the mycelia ("roots") of the mushroom. It may be feasible to have chickens pick the mycelia out. The remainder can be fed to cellulose digesting animals (Spinosa, 2008), which in turn could be eaten by humans.

\subsection{Trees}

Log structures could be constructed without industry to house mushrooms growing on logs. The heat released from the oxidation of the wood may provide enough heating, but biomass burning could always provide additional heating. It would be best to pull the trees down in order to expose many of the roots. We assume this additional biomass would counteract the biomass required for heating and other uses, so that the available amount of biomass for mushroom conversion is the aboveground mass ( $40 \%$ of the total vegetation (Food and Agriculture Organization, 2000)). This yields approximately $400 \mathrm{Gt}$ of dry equivalent. Then in order to have animals (or trucks with remaining diesel) pull the logs into structures, the logs should be severed from the root base with chainsaws.

There are other constraints associated with preparing the wood for mushroom growth, including making spawn (mushroom spores plus a growing medium), making holes for the spawn, putting the spawn in the holes, and sealing the holes to prevent competing organisms. Spawn can be based on sawdust, which could come from drilling). Humans could hand make human- or animal-powered drills. The worst-case scenario from a labor perspective is a hand-powered drill. One recommendation for the holes is $8 \mathrm{~mm}$ diameter, $40 \mathrm{~mm}$ depth, and $70 \mathrm{~mm}$ separation (Hazeltine and Bull, 2003). If it takes one minute to drill the hole, this yields 1.4 people fed by mushrooms per driller. However, the food production is over approximately 4 years, so there is significant labor investment. On the other hand, cattle can convert cellulose to food at 
approximately $11 \%$ efficiency (Denkenberger and Pearce, 2014), and we assume that $80 \%$ of the initial energy in the wood remains after mushroom production, which is the case for mushrooms grown on manure (Brendan Borrell, 2009). This would feed about nine times as many people as the mushrooms, and rabbit conversion efficiency would be even higher. Also, given the hole dimensions recommendation was for an electric drill, it may be possible to reduce drilling requirements without significantly degrading mushroom output.

The current technique for sealing the holes is using paraffin wax, but there would be insufficient supply of this. Therefore, an alternative is heating polymer film (possibly salvaged from landfills or produced from above-ground fossil fuels) and applying this. Sealing may not even be required, because once the mushrooms fruit, they break the seal. And they fruit many times over the years it takes to consume the logs.

A $\log 1 \mathrm{~m}$ long and $0.1 \mathrm{~m}$ in diameter will produce $\sim 1 \mathrm{~kg}$ of wet mushrooms over 4 years (Hazeltine and Bull, 2003). The dry density of wood is $0.5 \mathrm{~g} / \mathrm{cm}^{3}$ (Ragland et al., 1991) and mushrooms are $\sim 10 \%$ dry weight (Chang and Miles, 2000), so this yields $\sim 2 \%$ caloric efficiency. Therefore, outdoor mushroom growth is estimated to be $1 \%$ because of nonideal logs, pests, and inexperienced human error. This would provide three years of food for all people. Mushroom food production starts 6 months after the catastrophe as shown in Figure 1. With 1 billion people drilling over the years, the food produced from the mushrooms ramps up and peaks after about four years when the mushrooms stop producing. After that, freshly drilled trees start producing mushrooms, maintaining output. This would not require all the trees in the tropics, which is why the feasibility of preparing the trees in the tropics was considered with remaining gasoline.

Again, the waste from the mushrooms could be fed to cellulose digesters such as cattle and rabbits. The food production ramp curve of large cellulose digesters is the same as in previous work, though we truncate it at $25 \%$ because other food sources are sufficient at this point.

Rabbits have an age and sexual maturity of four months per litter, four litters per year (Zhiqiang and Xiaoyan, 2008). This results in an ideal growth rate of approximately 500\%. Taking the square root yields $150 \%$ per year growth rate. There are $~ 700$ million domesticated rabbits globally (Lukefahr, 1985), which is a significant underestimate of the total number of rabbits. With an average wet weight of $1 \mathrm{~kg}$, this represents an initial caloric production of $0.05 \%$ of human food.

Waste from these cellulose-digesting animals could be fed to chickens because the waste is high in bacteria, which can be digested by non-cellulose digesters. Disease risk from animals eating the excrement from other animals can be minimized by pasteurizing the waste, having the animals not closely related and by proper handling and cooking of animal products. However, we conservatively ignore the potential food production from this route.

The labor required for other steps for wood mushrooms production or other food production, such as cutting down trees if gasoline supply is insufficient, harvesting leaves, making temporary structures, etc. is significantly less than hand-drilling holes. 
It should be noted that, after the trees die and dry out, they would be susceptible to fire. Lightning can cause smoldering for several days before it transitions into active flaming combustion (Kasischke and Stocks, 2012). Since people will quickly distribute themselves to small plots of forest that they are converting into food, it should be feasible for them to survey the land for any smoke after each lightning storm. The smoldering combustion could likely be extinguished manually. Alternatively, it may be possible to install lightning rods to protect the forests, perhaps elevated by select trees or balloons filled with leaked natural gas. If these techniques are not successful, society could focus on trees in areas where it is frozen much of the time. Mushrooms could grow on trees inside log structures. Though lightning could ignite the warmed logs inside, there would be significant spacing between the structures and they would have a cold exterior, so fire spread would be unlikely.

\subsection{Fishing}

The ramp rate for fish is the same as in previous work (Denkenberger and Pearce, 2015), though this is added to current production of approximately $3 \%$ of the human food from fish. However, without industry, the catch rate would be significantly lower. Scaling Chinese total tonnage capacity of fishing vessels by its catch to the global catch yields current total tonnage capacity of fishing vessels of 54 million tons (FAO, 2014). Cargo ship capacity is approximately 800 million tons (Christiansen et al., 2004). With one third the speed (see Section 4.1) and all ships retrofitted to be fishing, this yields a maximum fish catch of $\sim 40 \%$ of human food.

Unfortunately, this would only persist until the nutrients in the upper layer of the ocean are depleted. We model this as a sudden reduction in fish catch after 2.5 years (see Figure 1), recognizing that it would actually be a slow reduction.

Some amount of production could be maintained by fertilizing the ocean. Since there are nitrogen-fixing bacteria in the ocean (Karl et al., 1997), we focus on phosphorus. Small fish are $\sim 4 \%$ phosphorus by dry weight (Santos et al., 2016). Unfortunately, there is very little phosphorus in wood ash (Karoline, 2012). However, there is roughly $2.5 \%$ phosphorus by weight in dried chicken manure (Ghaly, 2013). In the ocean iron fertilization experiments, only $\sim 7 \%$ of carbon initially sequestered is expected to fall to the ocean floor over a 100 year period (Gnanadesikan et al., 2003). Using this percentage to determine the efficiency of conversion of phosphorus into fish, this yields a $240 \%$ weight of dry manure to fertilize a given weight of dried fish. This means some ships would be dedicated to fertilizing, in addition to the fertilizer brought out by the fishing ships. Since the overall fish yield is significantly lower than in the upwelling case (see Figure 1), there would be sufficient ships. Though conversion to phosphorus could be lower efficiency, waste from other animals and humans could be used. Biomass fires could be used to dry the fish on the ship. It may be possible to concentrate the nutrients in the manure by removing residual fiber, requiring less shipping.

The chicken manure could instead be fed to mushrooms or cellulose digesters. However, fish would provide additional diet diversity. Also, the conversion efficiency (not counting the solar energy input) would be higher for fish. Of the dry feed of chickens, $\sim 50 \%$ is converted into dry weight of manure (McCall, 1980). ${ }^{1}$ The resulting fish output is shown in Figure 1.

\footnotetext{
${ }^{1}$ This statistic was originally from 1914, which could be appropriate for the loss of industry and for nonideal food for chickens.
} 
One way of increasing fish output during upwelling would be by reducing fishing transportation by relocating people to islands.

\subsection{Interactions}

Figure 1 shows one possible scenario for the deployment of various food sources. Obviously many more are possible, though the food sources dependent on the waste from other conversion processes are constrained because the waste must first be produced, and the preservation of those wastes to use later would be more difficult. The scenario shown attempts to make the food supply fairly consistent and also provide a diversity of foods at all times. Leaf extraction is ramped up to a high level to limit the use of stored food. Then the leaves killed by the catastrophe are consumed by the time agriculture becomes large. Mushrooms grown on leaves have similar behavior because they are largely depending on the waste from leaf extraction. This helps with diet diversification. Leaf extraction continues at a lower level based on agricultural residues, and this assumes that the dry weight of the agricultural residues that is not toxic is equal to the dry weight of the food grown. With six months of stored food, we chose a minimum of $150 \%$ of food requirements, which allowed some stored food to be consumed over the entire 10year period. Rabbits and ruminants are capped even though more food could be obtained from them with the copious mushroom-digested wood. After about five years, the safety margin becomes very large. This is fortunate because if burning of biomass is a significant problem, it would be more severe the further one goes from the time of the catastrophe. The actual food consumption can be smoother than this graph by storing alternate foods. After 10 years, agriculture could recover to pre-catastrophe levels. Therefore, we assume that alternate foods are ceased, and the practice of feeding edible food to animals reappears.

\subsection{Other potential food sources}

Having bacteria partially decompose lignocellulose (fiber) for noncellulose digesters (humans, chickens, and rats (the latter are partial cellulose digesters)) is less certain to succeed, especially without industry, so it is not considered here. Another food source considered in previous work was cellulose-digesting beetles. However, the ramping time was similar to rabbits considered here. And rabbits are superior from the perspectives of taste, social acceptability and ease of raising. Methane-digesting bacteria were also considered in previous work, but without industry, the supply of natural gas would be much smaller and the process would likely need to rely on industrial techniques. Furthermore, the technique of producing enzymes at scale to turn cellulose into sugar would also likely require industry. A new possibility is pyrolyzing wood to produce methane and hydrogen for bacteria. This also produces charcoal, meaning the conversion efficiency to bacteria would be lower. However, some amount of charcoal would be useful for heating and cooking. Also, this process would produce food far faster than mushroom softening of wood. Charcoal can be made without industry, but the growing of the bacteria would benefit from industrial techniques. Therefore, this food source is not quantified here.

Mushrooms could also grow on currently decomposing wood in forests and landfills and on peat (Rhodes, 2014). However, peat and to some extent landfills would put carbon dioxide into the air that would not otherwise make it there. Furthermore, people may reject food grown on landfill material. Competing organisms would be more difficult to control on currently decomposing wood. 
Other food sources not quantified here that could be analyzed for future work include seaweed and termites eating wood.

Still other food sources would require much more extensive preparation. Storing food would be very expensive and would exacerbate current malnutrition (Baum et al., 2015). Crops could be genetically engineered for cold and UV tolerance, but in order to produce a significant amount of food rapidly, either the crops need to be planted or a large amount stored.

\subsection{Diet Diversity}

People outside the tropics inland would have some diet diversity with leaf extract, mushrooms, and land animals. The majority of the fishing initially would be outside the tropics because that is where the ocean would upwell. People on the coast would therefore have fish and perhaps some seaweed. People in the tropics would have leaf extract, mushrooms, land animals, and plants. Therefore, some trade would be very beneficial for diet diversity.

\section{Nonfood needs}

Providing nonfood needs in this scenario is similar to the scenario of only losing industry, which has been covered previously (Abdelkhaliq et al., 2016). Here we only discuss additional challenges.

\subsection{Transportation}

Immediately after the catastrophe, there would likely be significant winds because the continents would cool off faster than the oceans. However, after this transient period, wind intensity is likely to be lower than normal because wind is generally driven by the sun. When the sun is $50 \%$ blocked, the winds driving the ships would be roughly $2 / 3$ as fast (Bardeen unpublished results). This means that the wind-powered vehicles could go only $2 / 3$ as fast as the case of no sun blocking (wind powered with no sun blocking was half as fast as with industry (Abdelkhaliq et al., 2016)), so overall this is one third as fast as currently.

The current global shipping traffic is 53,000 Gt moved 1 kilometer (Gt-km) (UNCTAD, 2009). This does not include the capacity of military and other vessels, which is conservative. With the slower speed in a catastrophe and being full both directions, duty cycle would be higher. However, it will take longer to load and unload without industry, so we assume duty cycle remains the same. With one third the speed of current ships the capacity would be $18,000 \mathrm{Gt}-\mathrm{km}$. If we consider $0.2 \mathrm{Gt}$ of food being required to be transported $12,000 \mathrm{~km}$ over the ocean, this would be $2,400 \mathrm{Gt}-\mathrm{km} / \mathrm{yr}$. Of course there would be other shipping requirements, but there is significant safety margin, which is why we assumed that nearly all merchant ships would be available for fishing. 
If this same $0.2 \mathrm{Gt}$ of food needs to be moved 4,000 $\mathrm{km}$ over land total (on both the producing and receiving continents), this is $800 \mathrm{Gt}-\mathrm{km} / \mathrm{yr}$. Barges could be kite powered at least part of the time, but modern ones are so large that it would be difficult for animals to pull them. Heavy trucks would also take many animals. However, with the low rolling resistance of rail $(0.0015$ (Toolbox, 2016)), not too many animals would be required to pull a single railcar. However, there is a limited number of rail cars. Therefore, we focus this analysis on light-duty vehicles (LDVs). There are 190 million LDVs in the United States (U.S. Department of Transportation, 2016), so if this is one quarter of the total, this is approximately 800 million globally. The average curb mass of cars in the U.S. is approximately $1500 \mathrm{~kg}$ (Wenzel, 2010). The average LDV in the U.S. would be heavier (because of vans, sport-utility vehicles, and pickup trucks), but we estimate that this number is reasonable for the average global LDV. A lower bound for the average cargo capacity is the mass of five people, roughly $350 \mathrm{~kg}$. The powertrain makes up about $28 \%$ of the curb mass (Roth et al., 2001). Some components other than the powertrain could be removed, but we conservatively ignore this. Therefore, when the powertrain is removed, the total cargo capacity would be $\sim 800 \mathrm{~kg}$. The rolling resistance of a high pressure tire on asphalt is approximately 0.01 (Toolbox, 2016). There are 1.4 billion cattle in the world. An ox can produce $450 \mathrm{~W}$ of useful power for six hours a day at $1 \mathrm{~m} / \mathrm{s}$ (Carruthers and Rodriguez, 1992). Though many of the cattle in the world are dairy, which would not be as strong as oxen, we assume this factor counteracts the conservatism of fraction cargo capacity. On level road, only approximately half a head of cattle would be required to pull the fully loaded LDV. Going up hills would require more, and we estimate average effort is twice as much as on the level. These assumptions yield approximately 11,000 Gt-km/yr inland transportation capability from cattle pulling LDVs. This is an order of magnitude greater than the food movement requirement. This would allow other inland movement such as manure out of the mid-latitude continents for ocean fertilization, wood from forests to burn to dry manure produced in grasslands, and wood from forests to the coasts to put on ships for drying the fish.

\subsection{Miscellaneous}

A further additional challenge is that with roughly half as much sun, there will be about half as much precipitation (Robock et al., 2007). However, since vegetation would die in most areas, runoff and groundwater recharge could be even greater than in the case with the sun. Because forests require significant precipitation, there would generally be surface water available nearby. However, in drier areas without infrastructure, a high-value use of the remaining fossil fuels would be drilling wells. Then people would lower a vessel into the well to retrieve water (and this could be done with existing wells as well (Abdelkhaliq et al., 2016)).

Another additional challenge would be clothing because of the inability to grow new fiber. There is a significant over supply of clothing currently, so it is unlikely to present a major challenge in the short term. One longer term solution is to wear animal skins, e.g. from the draft animals.

With the burning of biomass to heat buildings and loss of industrial firefighting, mass fires in cities could be a significant risk. The lower temperatures associated with the sun being obscured would reduce fire spread. Selective removal of buildings would also reduce the probability of mass fire. This would be consistent with many people having to move out of urban areas for food production.

\section{Discussion}


In previous work considering the 50\% sunblocking scenario with the retention of industry, agriculture was not considered. However, this work was too conservative considering the outputs predicted upon Tibetan agriculture. Now that here it has been demonstrated that agriculture could be important even without industry, obviously it could be important with industry. Rabbits would also be a promising option with industry.

If industry is restored before the smoke settles, this case reverts to the $50 \%$ sun with industry case, which is much less challenging. Also, if industry is not restored by the time the sun comes back out, this reverts to the no industry case, which again is less extreme.

In some cases, catastrophes can be correlated, and therefore much more likely to happen at the same time than if they were uncorrelated. One example of this is the use of solar radiation management, which reduces the amount of sunlight absorbed by the earth. This would combat climate change using techniques such as sulfate particles injected into the stratosphere. If this solar radiation management were stopped, there would be rapid warming of the climate (Matthews and Caldeira, 2007). Therefore, it is likely only to be stopped if there were some catastrophe (Baum et al., 2013). However, then society would have to contend both with the initial catastrophe and the rapid warming of the climate due to cessation of solar radiation management: "double catastrophe." The loss of industry would clearly mean the loss of solar radiation management. Of course the impact on agriculture of rapid warming is different than rapid cooling, increased UV and lower sunlight. However, many of the techniques discussed here could still be used.

A super crop pest (animal, e.g. insect) or pathogen could be spread globally in a coordinated attack (Madden and Wheelis, 2003). If the response were to restrict trade, this could cause the collapse of fossil-fuel-dependent industry in many areas. Even though this would not be a sunblocking scenario, the result would be similar to losing crops and industry.

Labor calculations indicate that most people could be dedicated to restoring industry. Also, this means a minority of people would need to be relocated. Generally since approximately twice as much food as required could be produced, this indicates that little relocation of people between continents would be required.

\section{Future work}

It would be preferable if the catastrophe could be prevented. There are steps to reduce the chances of nuclear war (Barrett et al., 2013). Also, there are interventions to reduce the risk of losing electricity and industry (Cole et al., 2016). But even if all this prevention and protection is feasible and justified, until it is all implemented, a backup plan is required.

We ignore the additional food sources of feeding food processing, retailing, and household waste to animals. Because there is significant safety margin in feeding everyone, even if food storage were at the minimum when the catastrophe hit, everyone could still be fed. Furthermore, it would be even easier to feed everyone if there were some warning before the catastrophe.

We leave the actual recovery time (and mechanism) from various catastrophes for future work. 
Experiments to be performed include sealing the holes in logs by heating a sheet of polymer. The other food sources could be further investigated. Experiments on lightning rods and fire surveillance would also be valuable. Demonstrating conversion of logs into mushrooms in $\log$ structures subjected to freezing conditions outside would be illuminating. Nutrition is future work, though we note that a similar diet was shown to be adequate (Griswold et al., 2016), and there are other methods of producing vitamins such as growing certain types of bacteria.

\section{Conclusions}

For combined sun blocking and industrial failure scenarios, the reduced output of conventional agriculture would present a threat of causing mass starvation. This study showed that one solution in the short term is extracting edible calories from killed leaves using distributed mechanical processes. Then a constrained food web could be formed where part of the remainder from this could be fed to chickens, and the rest coupled with leaf litter could have mushrooms grown on it. A second group of solutions is growing mushrooms on dead trees and the residue going to cellulose digesting animals such as cattle and rabbits. Typically in these catastrophes the sun is not blocked completely, so some agriculture would be possible based off of existing farming in extreme environments (e.g. growing UV and cold tolerant crops in the tropics). Furthermore, the cooling climate would cool the upper layer of the ocean, causing upwelling of nutrient-rich deep ocean water. This would facilitate algae growth in the ocean, feeding fish; retrofitting of ships to be sail powered could enable significant fishing. The results of this study show these solutions could enable the feeding of everyone given minimal preparation, and this preparation should be a high priority now.

\section{Acknowledgements}

The authors would like to acknowledge helpful discussions with Joseph Geddes, Carl Shulman and Charles Bardeen. Funding was provided by Tennessee State University, but this did not influence the research or publication process. The views in this paper are the authors' and are not necessarily the views of the Global Catastrophic Risk Institute.

\section{References}

Abdelkhaliq, M., Denkenberger, D., Cole, D., Griswold, M., Pearce, J., Taylor, A.R., 2016. Non Food Needs if Industry is Disabled, in: Proceedings of the 6th International Disaster and Risk Conference. Presented at the 6th International Disaster and Risk Conference, Davos, Switzerland.

Barrett, A.M., Baum, S.D., Hostetler, K.R., 2013. Analyzing and reducing the risks of inadvertent nuclear war between the United States and Russia. Sci Glob. Secur 21, 106133.

Baum, S.D., Denkenberger, D.C., Pearce, J.M., Robock, A., Winkler, R., 2015. Resilience to global food supply catastrophes. Environ. Syst. Decis. 1-13.

Baum, S.D., Maher, T.M., Haqq-Misra, J., 2013. Double catastrophe: Intermittent stratospheric geoengineering induced by societal collapse. Environ. Syst. Decis. 33, 168-180.

Beckstead, N., 2013. On the overwhelming importance of shaping the far future. Rutgers Univ. 
Board, S.S., 2008. Severe Space Weather Events--Understanding Societal and Economic Impacts: A Workshop Report. National Academies Press.

Bostrom, N., Cirkovic, M.M. (Eds.), 2008. Global Catastrophic Risks. Oxford University Press, New York.

Brendan Borrell, 2009. Making mushrooms environmentally friendly: Can science keep mushroom farmers from stinking up the Commonwealth of Pennsylvania? Sci. Am. 7.

Brown, T., Hatch, A.B., 2002. The value of rail intermodal to the US economy. Artic. Am. Assoc. Railr. Last Assess. Febr. 15, 2007.

Carruthers, I., Rodriguez, M., 1992. Tools for agriculture. Intermediate Technology Publishers. Chang, S.-T., Miles, P.G., 2000. Edible mushrooms and their cultivation. CRC Press.

Chang, S.T., Miles, P.G., 1984. A new look at cultivated mushrooms. Biosci. 34, 358-362.

Chen, Y.-C., Norsang, G., Pingcuo, N., Dahlback, A., Frette, Ø., Kjeldstad, B., Stamnes, K., Stamnes, J.J., 2013. Solar UV radiation measurements across the Tibetan Plateau. Presented at the RADIATION PROCESSES IN THE ATMOSPHERE AND OCEAN (IRS2012): Proceedings of the International Radiation Symposium (IRC/IAMAS), AIP Publishing, pp. 848-851.

Chester, C.V., Perry, A.M., Hobbs, B.F., 1988. Nuclear winter: implications for civil defense (No. 6399). Oak Ridge National Laboratory, Oak Ridge, Tennessee.

Christiansen, M., Fagerholt, K., Ronen, D., 2004. Ship routing and scheduling: Status and perspectives. Transp. Sci. 38, 1-18.

Cole, D.D., Denkenberger, D., Griswold, M., Abdelkhaliq, M., Pearce, J., 2016. Feeding

Everyone if Industry is Disabled, in: Proceedings of the 6th International Disaster and Risk Conference. Presented at the 6th International Disaster and Risk Conference, Davos, Switzerland.

Dartnell, L., 2014. The Knowledge: How to Rebuild Our World from Scratch. Random House.

Denkenberger, D., Pearce, J.M., 2014. Feeding Everyone No Matter What: Managing Food Security After Global Catastrophe. Academic Press.

Denkenberger, D.C., Pearce, J.M., 2015. Feeding everyone: Solving the food crisis in event of global catastrophes that kill crops or obscure the sun. Futures 72, 57-68.

Do, T., Anderson, K., Brorsen, B.W., 2010. The World's wheat supply. Okla. Coop. Ext. Serv.

Earth Policy Institute, 2011. Rising Meat Consumption Takes Big Bite out of Grain Harvest. Earth Policy Institute.

Energy Information Administration, 2016. Monthly Bulk Terminal and Blender Report (No. Form EIA-813).

FAO, 2014. The state of world fisheries and aquaculture. Food and Agriculture Organization of the United Nations.

Food and Agriculture Organization, 2000. Global Forest Resources Assessment. Food and Agriculture Organization (United Nations).

Foster, J.S., 2008. Report of the commission to assess the threat to the united states from electromagnetic pulse (emp) attack: Critical national infrastructures. DTIC Document.

Ghaly, 2013. DRYING POULTRY MANURE FOR POLLUTION POTENTIAL REDUCTION AND PRODUCTION OF ORGANIC FERTILIZER. Am. J. Environ. Sci. 9, 88-102. doi:10.3844/ajessp.2013.88.102

Gnanadesikan, A., Sarmiento, J.L., Slater, R.D., 2003. Effects of patchy ocean fertilization on atmospheric carbon dioxide and biological production. Glob. Biogeochem. Cycles 17, 1050. doi:10.1029/2002GB001940 
Goodin, D., 2016. First known hacker-caused power outage signals troubling escalation.

Griswold, M., Denkenberger, D., Abdelkhaliq, M., Cole, D., Pearce, J., Taylor, A.R., 2016. Vitamins in Agricultural Catastrophes, in: Proceedings of the 6th International Disaster and Risk Conference. Presented at the 6th International Disaster and Risk Conference, Davos, Switzerland.

Hazeltine, B., Bull, C., 2003. Field Guide to Appropriate Technology. Academic Press, San Francisco.

Hellman, M.E., 2008. Risk analysis of nuclear deterrence. Bent Tau Beta Pi.

Hurburgh, C., 2006. Moisture Basis Conversions for Grain Composition Data. Agric. Environ. Ext. Publ.

Jacquemoud, S., Ustin, S.L., Verdebout, J., Schmuck, G., Andreoli, G., Hosgood, B., 1996. Estimating leaf biochemistry using the PROSPECT leaf optical properties model. Remote Sens Env. 56, 194-202.

Kakani, V., Reddy, K., Zhao, D., Sailaja, K., 2003. Field crop responses to ultraviolet-B radiation: a review. Agric. For. Meteorol. 120, 191-218.

Karl, D., Letelier, R., Tupas, L., Dore, J., Christian, J., Hebel, D., 1997. The role of nitrogen fixation in biogeochemical cycling in the subtropical North Pacific Ocean. Nature 388, 533-538.

Karoline, K., 2012. Chemistry of wood ash leachates and the filter effect of soil columns on leachate composition. University of Natural Resources and Life Sciences, Vienna, Austria.

Kasischke, E.S., Stocks, B.J., 2012. Fire, climate change, and carbon cycling in the boreal forest. Springer Science \& Business Media.

Kennedy, D., Leaf for Life, 1993. Leaf concentrate: A field guide for small-scale programs.

Kushner, D., 2013. The real story of stuxnet. IEEE Spectr. 50, 48-53. doi:10.1109/MSPEC.2013.6471059

LaFontaine, H., Zimmerman, F.P., 1989. Construction of a simplified wood gas generator for fueling internal combustion engines in a petroleum emergency. DTIC Document.

Langer, R.W., 1994. Grow It!

Lukefahr, S., 1985. A note on an estimate of the world's domestic rabbit population. J. Appl. Rabbit Res. 8, 157.

Madden, L.V., Wheelis, M., 2003. The threat of plant pathogens as weapons against U.S. crops. Annu Rev Phytopathol 41, 155-176. doi:10.1146/annurev.phyto.41.121902.102839

Magnusson, R., Nilsson, C., Andersson, K., Andersson, B., Gieling, R., Wiberg, K., Östman, C., Rannug, U., 2000. Determination of chemical composition and mutagenicity in particles from chainsaw exhaust. Experimental set-up, stability and results from two different fuels. Environ. Technol. 21, 819-829.

Matthews, H.D., Caldeira, K., 2007. Transient climate-carbon simulations of planetary geoengineering 104, 9949-9954.

McCall, W.W., 1980. Chicken manure.

Meadows, D.H., Randers, J., Meadows, D.L., 2004. Limits to Growth: The 30 Year Update. Chelsea Green Publishing Company, White River Junction, VT.

Mekhaldi, F., Muscheler, R., Adolphi, F., Aldahan, A., Beer, J., McConnell, J.R., Possnert, G., Sigl, M., Svensson, A., Synal, H.-A., 2015. Multiradionuclide evidence for the solar origin of the cosmic-ray events of AD 774/5 and 993/4. Nat. Commun. 6. 
Miller, D., 2003. Tibet environmental analysis. Background paper in preparation for USAID's program. USAID Bureau for Asia and Near East. US Agency for International Development (USAID) Website.

Mills, M.J., Toon, O.B., Turco, R.P., Kinnison, D.E., Garcia, R.R., 2008. Massive global ozone loss predicted following regional nuclear conflict. Proc Natl Acad Sci USA 105, 53075312.

Ragland, K.W., Aerts, D.J., Baker, A.J., 1991. Properties of wood for combustion analysis. Bioresour. Technol 37, 161-168.

Rhodes, C.J., 2014. Mycoremediation (bioremediation with fungi)-growing mushrooms to clean the earth. Chem. Speciat. Bioavailab. 26, 196-198.

Robinson, R.A., 2007. Crop histories. Sharebooks Pub.

Robock, A., Oman, L., Stenchikov, G.L., 2007. Nuclear winter revisited with a modern climate model and current nuclear arsenals: Still catastrophic consequences. J Geophys Res Atmos 112, 1984-2012.

Roth, R., Clark, J., Kelkar, A., 2001. Automobile bodies: Can aluminum be an economical alternative to steel? Jom 53, 28-32.

Santos, T.M. de A., Terra, B. de F., Zandonà, E., Santaella, S.T., Rezende, C.F., 2016. Phosphorus body content in an herbivorous fish in environments with different trophic state. J. Limnol. 0.

Spinosa, R., 2008. Fungi and sustainability. Fungi 1.

Tilman, D., Cassman, K.G., Matson, P.A., Naylor, R., Polasky, S., 2002. Agricultural sustainability and intensive production practices. Nature 418, 671-677. doi:10.1038/nature01014

Toolbox, E., 2016. Rolling Resistance [WWW Document]. URL http://www.engineeringtoolbox.com/rolling-friction-resistance-d_1303.html

UNCTAD, 2009. Review of maritime transport 2009. United Nations conference on trade and development, New York.

United States Department of Agriculture, 2006. USDA national nutrient database for standard reference release 17 .

U.S. Department of Transportation, 2016. National Transportation Statistics. U.S. Bureau of Transportation Statistics.

Wenzel, T.P., 2010. Analysis of the relationship between vehicle weight/size and safety, and implications for federal fuel economy regulation. Lawrence Berkeley Natl. Lab.

Zhiqiang, L., Xiaoyan, C., 2008. Rabbit resources of China, in: MEKARN Rabbit Conference. Presented at the Organic rabbit production from forages, Cantho University, Vietnam. 